\title{
Avaliação agronômica de híbridos interespecíficos entre capim-elefante e milheto
}

\author{
Fausto de Souza Sobrinho(1), Antônio Vander Pereira ${ }^{(1)}$, Francisco José da Silva Ledo ${ }^{(1)}$, Milton Andrade Botrel(1), \\ Jackson Silva e Oliveira ${ }^{(1)}$ e Deise Ferreira Xavier ${ }^{(1)}$
}

(1)Embrapa Gado de Leite, Rua Eugênio do Nascimento, ㄲo 610, CEP 36038-330 Juiz de Fora, MG. E-mail: fausto@cnpgl.embrapa.br, avanderp@cnpgl.embrapa.br, ledo@cnpgl.embrapa.br, mbotrel@cnpgl.embrapa.br, jackoliv@cnpgl.embrapa.br, dfxavier@cnpgl.embrapa.br

Resumo - O objetivo deste trabalho foi avaliar o comportamento agronômico de híbridos entre capim-elefante (Pennisetum purpureum Schum.) e milheto (P. glaucum (E.) Leek), a fim de determinar seu potencial para o melhoramento da forragem e a seleção de híbridos para futuras avaliações. Foram utilizadas 12 cultivares de milheto e 11 clones de capim-elefante, cruzados em esquema de dialelo parcial. As 132 combinações híbridas, além de duas testemunhas, foram avaliadas em experimentos em blocos casualizados, com três repetições. Anotaram-se dados de produção de matéria seca, altura de plantas, porcentagem de matéria seca, relação entre folha e caule e de qualidade da forragem (porcentagem de proteína bruta, porcentagem de fibra em detergente neutro e ácido e digestibilidade in vitro da matéria orgânica). Foi verificada existência de variabilidade entre os híbridos interespecíficos de capim-elefante e milheto, na maioria das características. A superioridade de alguns híbridos, em relação às testemunhas, demonstra o potencial do cruzamento entre P. purpureum e P. glaucum para a obtenção de cultivares melhoradas. Considerando-se tanto características de produção como de qualidade da forragem, os melhores híbridos avaliados foram 108 (F91-2-5 x M-60), 53 (F93-4-2 x M-27), 35(F94-28-3 x M-42), 36 (F94-28-3 x M-60) e 4 (F92-101-2 x M-35).

Termos para indexação: Pennisetum purpureum, Pennisetum glaucum, melhoramento genético, qualidade da forragem.

\section{Agronomic evaluation of interespecific hybrids of elephant grass and pearlmillet}

\begin{abstract}
The objective of this work was to evaluate the agronomic performance of hybrid from elephant grass (Pennisetum purpureum Schum.) and pearlmillet (P. glaucum (E.) Leek) in order to determine its potential for forage enhancement. Twelve cultivars of pearlmillet and 11 clones of elephant grass were crossed using a partial dialel design. The 132 hybrids combinations along with two test hybrids were evaluated in casual block design experiment with three replications. Dry matter production, plant height, dry matter percent, leaf:stem relation and forage quality information, such as crude protein, fiber percentage in neutral and in acid detergent and in vitro organic matter digestibility were recorded. There was variability between the interspecific hybrids of elephant grass and pearlmillet for most of the studied parameters. The high performance of some experimental hybrids, compared to the two test hybrids, shows the potential of $P$. purpureum and $P$. glaucum crosses to develop better cultivars. Considering forage productivity and quality, the best hybrids were 108 (F91-2-5 x M-60), 53 (F93-4-2 x M-27), 35(F94-28-3 x M-42), 36 (F94-28-3 x M-60) and 4(F92-101-2 x M-35).
\end{abstract}

Index terms: Pennisetum purpureum, Pennisetum glaucum, breeding, forage quality.

\section{Introdução}

O potencial produtivo do capim-elefante (Pennisetum purpureum Schum.), associado a outras características forrageiras favoráveis, tais como boa qualidade, palatabilidade, vigor e persistência, tem estimulado não só o cultivo dessa espécie como também o seu melhoramento genético visando ao desenvolvimento de cultivares para utilização sob pastejo e para capineiras.

O capim-elefante contribui para o aumento da produção de leite (Deresz, 1999) e de carne, sendo uma es- pécie amplamente difundida por todo o Brasil, cultivada em condições ambientais bastante divergentes, apesar de existirem poucas cultivares melhoradas disponíveis, especialmente para uso sob pastejo rotativo (Pereira et al., 2001).

A obtenção de cultivares melhoradas é uma necessidade comum a produtores de leite de todo o País, e a procura por novas variedades de forrageiras adaptadas aos diferentes ecossistemas é intensa. Entre os atributos desejados, buscam-se cultivares com propagação por 
meio de sementes, resistência à cigarrinha-das-pastagens, maior velocidade de crescimento, maior produtividade, melhor qualidade nutricional, tolerância a solos de baixa fertilidade e distribuição mais eqüitativa da produção de matéria seca durante o ano (Pereira et al., 2003).

A proximidade genética entre o capim-elefante e 0 milheto (Pennisetum glaucum) possibilita a obtenção de híbridos entre estas duas espécies com relativa facilidade. Deste cruzamento resulta um híbrido interespecífico triplóide, estéril, que, morfologicamente, se assemelha ao capim-elefante e apresenta algumas características intermediárias entre as duas espécies parentais (Hanna, 1999). Esta combinação genética busca reunir no híbrido determinadas características desejáveis do milheto, tais como qualidade da forragem, tolerância à seca e resistência às doenças, com a rusticidade, agressividade, perenidade e a elevada produção de matéria seca do capim-elefante (Schank et al., 1993; Diz, 1994). Segundo Jauhar (1981), a forragem destes híbridos interespecíficos apresenta melhor aceitação pelos bovinos que o próprio capim-elefante.

O objetivo deste trabalho foi avaliar o comportamento agronômico de híbridos entre capim-elefante e milheto visando à determinação do potencial para melhoramento da forragem e à seleção de híbridos para futuras avaliações.

\section{Material e Métodos}

O trabalho foi conduzido no Campo Experimental de Coronel Pacheco, MG, da Embrapa Gado de Leite, no período de janeiro de 2000 a maio de 2003. Inicialmente foram selecionados diferentes genótipos de milheto e de capim-elefante para a realização dos cruzamentos interespecíficos. Quanto ao capim-elefante, foram se- lecionados materiais já cultivados e os mais promissores no programa de melhoramento de forrageiras da Embrapa Gado de Leite. No caso do milheto, a prioridade foi para os genótipos que apresentavam sementes grandes, florescimento tardio e também boas características forrageiras, tais como porcentagem de proteína e produção de matéria seca.

Foram selecionadas 12 cultivares de milheto e 11 clones de capim-elefante, constituindo dois grupos diferentes. Realizaram-se cruzamentos controlados, utilizando-se sempre o milheto como parental feminino, em esquema de dialelo parcial, visando à obtenção das 132 combinações híbridas possíveis (Tabela 1). As infloresências foram protegidas com saco de papel e, por ocasião da antese (aparecimento dos estigmas), realizou-se a polinização com pólen do capim-elefante e colocou-se nova proteção. Como a maturação dos estigmas ocorre cerca de 8 a 10 dias antes da liberação do pólen no milheto (protoginia), e a polinização artificial foi realizada com grande quantidade de pólen, admitiuse que todas as sementes geradas foram oriundas do cruzamento interespecífico. As sementes de cada cruzamento foram plantadas diretamente no campo, em linhas de $10 \mathrm{~m}$ de comprimento, para a seleção das melhores plantas. Utilizaram-se, aproximadamente, cem sementes de cada combinação, obtendo-se, em média, 50 plântulas. A seleção das melhores plantas foi realizada cerca de 90 dias após a semeadura, com base em características fenotípicas como altura de plantas, vigor e número de perfilhos, eliminando-se aquelas muito semelhantes ao milheto pela possibilidade de serem oriundas de autofecundação. Posteriormente as plantas selecionadas foram clonadas para a instalação do experimento. Cada cruzamento foi representado por

Tabela 1. Relação das 132 combinações híbridas (tratamentos) geradas pelo cruzamento, em esquema de dialelo parcial, das 12 cultivares de milheto (vertical) e 11 clones de capim-elefante (horizontal).

\begin{tabular}{|c|c|c|c|c|c|c|c|c|c|c|c|}
\hline Cultivar & F92-101-2 & BAG-75 & F94-28-3 & F93-8-1 & F93-4-2 & BAG19 & F91-27-1 & BAG-27 & F91-2-5 & F92-97-3 & BAG-64 \\
\hline M-29 & 1 & 13 & 25 & 37 & 49 & 61 & 73 & 85 & 97 & 109 & 121 \\
\hline M-36 & 2 & 14 & 26 & 38 & 50 & 62 & 74 & 86 & 98 & 110 & 122 \\
\hline M-59 & 3 & 15 & 27 & 39 & 51 & 63 & 75 & 87 & 99 & 111 & 123 \\
\hline M-35 & 4 & 16 & 28 & 40 & 52 & 64 & 76 & 88 & 100 & 112 & 124 \\
\hline M-27 & 5 & 17 & 29 & 41 & 53 & 65 & 77 & 89 & 101 & 113 & 125 \\
\hline M-60 & 6 & 18 & 30 & 42 & 54 & 66 & 78 & 90 & 102 & 114 & 126 \\
\hline M-31 & 7 & 19 & 31 & 43 & 55 & 67 & 79 & 91 & 103 & 115 & 127 \\
\hline M-41 & 8 & 20 & 32 & 44 & 56 & 68 & 80 & 92 & 104 & 116 & 128 \\
\hline M-30 & 9 & 21 & 33 & 45 & 57 & 69 & 81 & 93 & 105 & 117 & 129 \\
\hline M-40 & 10 & 22 & 34 & 46 & 58 & 70 & 82 & 94 & 706 & 118 & 130 \\
\hline M-42 & 11 & 23 & 35 & 47 & 59 & 71 & 83 & 95 & 107 & 119 & 131 \\
\hline M-60 & 12 & 24 & 36 & 48 & 60 & 72 & 84 & 96 & 108 & 120 & 132 \\
\hline
\end{tabular}


8-10 plantas clonadas. Como testemunhas foram utilizadas as cultivares de capim-elefante Pioneiro e Cameroon.

O experimento foi instalado num solo de meia encosta, classificado como Argissolo Vermelho-Amarelo, distrófico, textura argilo-arenosa. A calagem foi realizada três meses antes da implantação do experimento, baseada nos resultados da análise do solo para elevação da saturação de bases para 70\%, seguida de gradagem, conforme recomendações para a cultura (Comissão..., 1999). Como adubação de plantio, utilizaramse $100 \mathrm{~kg} \mathrm{ha}^{-1}$ de $\mathrm{P}_{2} \mathrm{O}_{5}, 30 \mathrm{~kg} \mathrm{ha}^{-1}$ de $\mathrm{K}_{2} \mathrm{O}$ e $15 \mathrm{~kg} \mathrm{ha}^{-1}$ de $\mathrm{N}$, incorporada no fundo do sulco. Após 50 dias do plantio, complementou-se a adubação com cobertura de $30 \mathrm{~kg} \mathrm{ha}^{-1}$ de $\mathrm{K}_{2} \mathrm{O}$ e $25 \mathrm{~kg} \mathrm{ha}^{-1}$ de N. Após cada corte, foram efetuadas adubações em cobertura com $60 \mathrm{~kg} \mathrm{ha}^{-1}$ de $\mathrm{K}_{2} \mathrm{O}$ e $50 \mathrm{~kg} \mathrm{ha}^{-1}$ de $\mathrm{N}$, e adubação fosfatada a lanço no início da época das águas (100 kg ha-1 de $\left.\mathrm{P}_{2} \mathrm{O}_{5}\right)$. Empregou-se o delineamento de blocos ao acaso, com três repetições e parcelas de uma linha de quatro metros de comprimento, com área útil de $3 \mathrm{~m}$ lineares.

O corte de uniformização foi realizado em 10/9/2001, a uma altura de aproximadamente $10 \mathrm{~cm}$ do solo. Posteriormente realizaram-se oito cortes de avaliação, na mesma altura do corte de uniformização, nos meses de novembro de 2001, fevereiro, abril, junho, outubro e dezembro de 2002 e fevereiro e maio de 2003, com intervalos de 72, 73, 66, 92, 97, 65, 67 e 81 dias de crescimento, respectivamente. Em cada corte foram avaliadas a altura das plantas (do solo até a curvatura da última folha completamente expandida), a produção de massa verde total (MVT $-\mathrm{t} \mathrm{ha}^{-1}$ ) e a porcentagem de massa seca total (PMS), obtida após a secagem em estufa a $60^{\circ} \mathrm{C}$ por 72 horas. A partir dos dados dessas duas últimas características, foram obtidas as estimativas da matéria seca total (MST - $\left.\mathrm{t} \mathrm{ha}^{-1}\right)$ e da relação folha/caule (RFC) com base na matéria seca. Os dados da relação folha/caule foram coletados apenas nos quatro primeiros cortes.

Em cada um dos oito cortes, foram realizadas análises estatísticas, considerando-se o modelo de blocos ao acaso, envolvendo os dados de cada uma das características avaliadas. Posteriormente, realizou-se a análise conjunta com os dados de todos os cortes, considerando-se o esquema de parcelas subdivididas no tempo (Ramalho et al., 2000). O modelo estatístico empregado foi:

$\mathrm{Y}_{\mathrm{ijk}}=\mu+\mathrm{b}_{\mathrm{j}}+\mathrm{p}_{\mathrm{i}}+\mathrm{c}_{\mathrm{k}}+(\mathrm{bp})_{\mathrm{ij}}+(\mathrm{bc})_{\mathrm{jk}}+(\mathrm{pc})_{\mathrm{ik}}+\varepsilon_{\mathrm{ij}}$ em que, $\mu$ é a média geral do ensaio; $b_{j}$ é o efeito do bloco j; $p_{i}$ é o efeito do híbrido i; $c_{k}$ é o efeito do corte $k$; (bp) $)_{\mathrm{ij}}$ é o efeito da interação entre híbrido i e o bloco j; (bc) ${ }_{j k}$ é o efeito da interação entre o corte k e o bloco j; $(\mathrm{pc})_{\mathrm{ik}}$ é o efeito da interação entre o híbrido i e o corte $\mathrm{k}$; e $\varepsilon_{\mathrm{ij}}$ é o erro experimental.

No terceiro corte, foram coletadas amostras para a realização de análises de características bromatológicas, as quais foram efetuadas por meio da espectrofotometria próxima do infravermelho (NIRS). As características mensuradas foram: porcentagem de proteína bruta (PB), porcentagem de fibra em detergente neutro (FDN) e em detergente ácido (FDA) e digestibilidade in vitro da matéria orgânica (DIVMO). Procedeu-se à análise de variância em diferentes características, considerandose o delineamento de blocos casualizados com três repetições.

Para identificar as melhores combinações, foi utilizado um índice de seleção (IS) fundamentado no somatório das classificações dos tratamentos para as diferentes características consideradas. Assim, os melhores híbridos serão aqueles que apresentarem menores somas no IS, indicando que foram bem classificados na maioria das características. Foram construídos três índices: o primeiro, baseado nas características de produção (IS produção), ou seja, produção de matéria seca, altura de plantas, porcentagem de matéria seca e RFC; o segundo, utilizando apenas as características bromatológicas (IS bromat.); e o terceiro, associando todas as características mensuradas (IS geral), atribuindo-se pesos iguais às diferentes características consideradas.

\section{Resultados e Discussão}

Em todas as análises estatísticas individuais (cortes), observou-se significância da fonte de variação híbridos, evidenciando ampla variabilidade entre os cruzamentos interespecíficos de capim-elefante e milheto quanto a características relacionadas à produção. Nas análises conjuntas, envolvendo os dados dos diferentes cortes, também foram constatadas diferenças significativas entre os híbridos para todas as características. Houve significância também para os cortes de avaliação, indicando que as características agronômicas dos híbridos interespecíficos variam de acordo com a época de corte.

A interação entre híbridos e cortes foi significativa, evidenciando que o comportamento dos híbridos não é consistente nos cortes sucessivos, ou seja, existem diferenças entre as médias dos híbridos, ou na classificação de seus desempenhos, nos diferentes cortes. Por se 
tratar de uma cultura perene, normalmente implantada para utilização durante alguns anos, as cultivares de capim-elefante devem se apresentar produtivas por todo o cultivo. Por isso, embora tenha sido verificada interação significativa entre híbridos x cortes, o interessante para o produtor é que os genótipos tenham desempenho mais estável durante os diferentes cortes. Assim, os resultados serão discutidos em função das médias obtidas nas análises conjuntas envolvendo os oito cortes.

A média de produção de matéria seca dos materiais estudados nos oito cortes de avaliação foi de 7,45 t ha-1. Resultado semelhante foi obtido por Santos et al. (2003), avaliando a produtividade da cultivar Pioneiro nas condições da Zona de Mata de Pernambuco, onde esta cultivar floresceu precocemente e foi inferior aos genótipos locais que foram selecionados para aquelas condições (Freitas, 2000). Santos et al. (1994), avaliando 41 clones de capim-elefante e seus híbridos com milheto no SemiÁrido de Pernambuco, obtiveram média de produção de MS de 12,6 $\mathrm{t} \mathrm{ha}^{-1}$. Considerando-se apenas os oito híbridos entre capim-elefante e milheto, a média de produção foi de $10,6 \mathrm{t} \mathrm{ha}^{-1}$, cerca de $42 \%$ superior à obtida neste trabalho. Essa superioridade se deve, provavelmente, ao maior intervalo entre cortes utilizado por Santos et al. (1994), permitindo maior crescimento e acúmulo de matéria seca.

A amplitude de variação foi de 6,97 tha-1de MS e os híbridos foram divididos em seis grupos pelo teste de Scott-Knott, com médias de 15,26, 12,57, 10,75, 8,83, 7,03 e 4,82 t ha-1 (Tabela 2). Os híbridos 119, 53 e 128 mostraram-se tão produtivos quanto a cultivar Cameroon (testemunha), entretanto, nenhum dos cruzamentos avaliados conseguiu igualar-se à cultivar Pioneiro. Botrel et al. (2000) constataram a superioridade de produção de matéria seca da cultivar Pioneiro, comparando 20 clones de capim-elefante selecionados na Embrapa Gado de Leite. A cultivar Pioneiro foi desenvolvida especificamente para as condições ambientais do local de avaliação desse experimento, além de apresentar boa estabilidade de produção nas diferentes épocas do ano (Pereira et al., 1997). Os resultados alcançados pela cultivar Pioneiro reforçam a importância da avaliação regional no processo de seleção de clones de capim-elefante (Freitas, 2000).

Também quanto à altura das plantas, observou-se separação das médias dos híbridos em quatro grupos distintos (Tabela 2). A média de cada um dos grupos foi de 1,59 m, 1,72 m, 1,82 m e 1,98 m. A média geral da altura de plantas, considerando-se os oito cortes de avaliação, foi de 1,66 m, com amplitude de variação de 0,53 m, sendo o híbrido mais baixo o 29, com 1,18 m. Resultados semelhantes para altura de plantas foram relatados por Santos et al. (1994), avaliando híbridos entre capim-elefante e milheto no Semi-Árido de Pernambuco.

A porcentagem de matéria seca (PMS) média foi de $24,66 \%$, oscilando de $21,68 \%$, no híbrido 60 , a $28,47 \%$ no 95. Ocorreu divisão dos híbridos em dois grupos pelo teste de Scott-Knott, com médias de 23,83\% e 26,31\% (Tabela 2). Santos et al. (2001), avaliando a composição química do capim-elefante cv. Roxo, encontraram PMS média de 19,7\% e 17,4\% no período seco e chuvoso, respectivamente. A maior PMS observada, em relação aos resultados obtidos por Santos et al. (2001), confirma o potencial forrageiro dos híbridos avaliados, reforçando a contribuição do milheto no melhoramento do capim-elefante (Schank et al., 1993).

A média da relação folha e caule foi de 0,76 , com o híbrido 79 apresentando a menor $\operatorname{RFC}(0,43)$ e o 57 , a maior $(1,76)$. As médias dos híbridos foram divididas em quatro grupos com amplitude de variação de 1,33 e média de cada grupo de 0,67, 0,90, 1,28 e 1,76. Na Tabela 2, onde estão apenas os 40 híbridos mais produtivos, estão apresentados os híbridos classificados nos grupos c e d para a RFC, pelo teste de Scott-Knott. Queiroz Filho et al. (2000) encontraram RFC entre 2,9 e 0,8, para idades de corte de 40 a 100 dias na cultivar Roxo de capim-elefante. No intervalo de corte de 80 dias, semelhante à média dos cortes desse experimento, a RFC foi de 1,1, superior às duas testemunhas utilizadas. Em outro trabalho, Santos et al. (1994) obtiveram RFC média em oito híbridos interespecíficos (capim-elefante $\mathrm{x}$ milheto) de $0,55,38,2 \%$ inferior à obtida neste trabalho $(0,76)$.

Associando-se a RFC e a PMS obtidas, acredita-se que os híbridos avaliados apresentaram PMS superior aos relatados por Santos et al. (2001), justamente por possuírem mais caule do que folhas (menor RFC), uma vez que os caules possuem mais fibras que as folhas (Botrel et al., 2000; Deschamps et al., 2001). Apesar disso, alguns híbridos interespecíficos apresentaram RFC 
superiores aos melhores resultados apresentados. A média de RFC do melhor híbrido avaliado (57) foi 2,9 vezes maior que a cultivar Pioneiro e quase duas vezes maior que o Cameroon. Esses resultados fornecem um indicativo da qualidade superior da forragem de alguns híbridos interespecíficos em relação ao capim- elefante, uma vez que as folhas possuem melhor qualidade que o caule (Deschamps et al., 2001) e esses híbridos apresentam melhor RCF que as testemunhas utilizadas.

Uma observação importante refere-se ao comportamento médio dos materiais ao longo dos sucessivos cortes. No cruzamento entre capim-elefante (espécie pe-

Tabela 2. Médias gerais dos 40 melhores híbridos interespecíficos entre capim-elefante e milheto e das duas testemunhas para a produção de matéria seca total (MST - $\mathrm{t} \mathrm{ha}^{-1} \operatorname{corte}^{-1}$ ) e respectivas médias de altura de plantas (Alt $-\mathrm{m}$ ), porcentagem de matéria seca (PMS), relação entre folha e caule (RFC), proteína bruta (PB - \%), fibra detergente neutro (FDN - \%), fibra detergente ácido (FDA - \%), e digestibilidade in vitro da matéria orgânica (DIVMO)(1).

\begin{tabular}{|c|c|c|c|c|c|c|c|c|}
\hline Híbrido & MST & Alt & $\% \mathrm{MS}$ & RFC & PB & FDN & FDA & DIVMO \\
\hline 128 & $13,06 b$ & $1,94 a$ & $25,99 a$ & $0,62 \mathrm{c}$ & $5,27 \mathrm{a}$ & $78,64 a$ & $51,82 b$ & $40,23 a$ \\
\hline 53 & $12,47 b$ & $1,77 \mathrm{c}$ & $24,30 \mathrm{~b}$ & $0,85 b$ & $5,45 a$ & $76,95 a$ & $48,30 \mathrm{~b}$ & $46,20 \mathrm{a}$ \\
\hline 119 & $12,20 \mathrm{~b}$ & $1,81 \mathrm{~b}$ & $23,74 b$ & $0,60 \mathrm{c}$ & $3,42 \mathrm{a}$ & $79,29 a$ & $50,49 b$ & $38,97 \mathrm{a}$ \\
\hline 129 & $11,05 \mathrm{c}$ & $1,99 a$ & $24,01 b$ & $0,61 \mathrm{c}$ & $3,18 \mathrm{a}$ & $80,02 \mathrm{a}$ & $51,32 b$ & $36,91 \mathrm{a}$ \\
\hline 78 & $11,01 \mathrm{c}$ & $1,81 \mathrm{~b}$ & $27,66 \mathrm{a}$ & $0,49 \mathrm{c}$ & $5,80 \mathrm{a}$ & $76,80 \mathrm{a}$ & $49,35 b$ & $46,45 a$ \\
\hline 108 & $10,94 \mathrm{c}$ & $1,92 \mathrm{a}$ & $22,50 \mathrm{~b}$ & $0,81 \mathrm{c}$ & $5,65 \mathrm{a}$ & $75,45 a$ & $46,60 \mathrm{a}$ & $43,65 \mathrm{a}$ \\
\hline 116 & $10,72 \mathrm{c}$ & $1,66 \mathrm{c}$ & $23,66 b$ & $0,72 \mathrm{c}$ & $4,57 \mathrm{a}$ & $77,68 \mathrm{a}$ & $48,77 \mathrm{~b}$ & $42,60 \mathrm{a}$ \\
\hline 75 & $10,71 \mathrm{c}$ & $1,80 \mathrm{~b}$ & $23,61 b$ & $0,69 \mathrm{c}$ & $5,10 \mathrm{a}$ & $79,65 a$ & $49,25 b$ & $40,70 \mathrm{a}$ \\
\hline 56 & $10,70 \mathrm{c}$ & $1,71 \mathrm{c}$ & $24,21 b$ & $0,79 \mathrm{c}$ & $4,65 a$ & $78,55 \mathrm{a}$ & $48,90 \mathrm{~b}$ & $41,60 \mathrm{a}$ \\
\hline 66 & $10,66 \mathrm{c}$ & $1,66 \mathrm{c}$ & $24,45 b$ & $0,87 b$ & $4,55 \mathrm{a}$ & $77,15 \mathrm{a}$ & $47,50 \mathrm{a}$ & $48,70 \mathrm{a}$ \\
\hline 132 & $10,60 \mathrm{c}$ & $1,60 \mathrm{~d}$ & $23,47 b$ & $0,88 b$ & $3,88 \mathrm{a}$ & $75,20 \mathrm{a}$ & $45,97 \mathrm{a}$ & $50,63 \mathrm{a}$ \\
\hline 36 & $10,58 \mathrm{c}$ & $1,76 \mathrm{c}$ & $25,35 \mathrm{a}$ & $0,77 \mathrm{c}$ & $5,45 a$ & $78,70 \mathrm{a}$ & $48,10 \mathrm{a}$ & $48,50 \mathrm{a}$ \\
\hline 94 & $10,54 \mathrm{c}$ & $1,83 \mathrm{~b}$ & $25,61 \mathrm{a}$ & $0,71 \mathrm{c}$ & $3,35 a$ & $76,25 a$ & $47,85 \mathrm{a}$ & $42,70 \mathrm{a}$ \\
\hline 101 & $10,46 \mathrm{c}$ & $1,97 \mathrm{a}$ & $27,04 \mathrm{a}$ & $0,74 \mathrm{c}$ & $5,00 \mathrm{a}$ & $80,40 \mathrm{a}$ & $50,30 \mathrm{~b}$ & $42,05 a$ \\
\hline 18 & $10,44 \mathrm{c}$ & $1,74 \mathrm{c}$ & $27,19 a$ & $0,62 \mathrm{c}$ & $6,70 \mathrm{a}$ & $76,10 \mathrm{a}$ & $48,75 b$ & $47,35 \mathrm{a}$ \\
\hline 115 & $10,04 d$ & $1,71 \mathrm{c}$ & $24,78 b$ & $0,71 \mathrm{c}$ & $5,37 \mathrm{a}$ & $78,93 a$ & $48,62 b$ & $45,03 \mathrm{a}$ \\
\hline 95 & $9,88 \mathrm{~d}$ & $1,74 \mathrm{c}$ & $28,47 \mathrm{a}$ & $0,50 \mathrm{c}$ & $6,50 \mathrm{a}$ & $79,80 \mathrm{a}$ & $49,95 b$ & $44,50 \mathrm{a}$ \\
\hline 106 & $9,80 \mathrm{~d}$ & $1,73 \mathrm{c}$ & $23,88 b$ & $0,95 b$ & $3,95 \mathrm{a}$ & $78,35 \mathrm{a}$ & $48,90 \mathrm{~b}$ & $36,60 \mathrm{a}$ \\
\hline 35 & $9,74 d$ & $1,77 \mathrm{c}$ & $24,21 b$ & $0,83 b$ & $4,85 \mathrm{a}$ & $75,45 a$ & $47,20 \mathrm{a}$ & $45,60 \mathrm{a}$ \\
\hline 27 & $9,56 \mathrm{~d}$ & $1,74 \mathrm{c}$ & $22,44 b$ & $0,76 \mathrm{c}$ & $5,25 \mathrm{a}$ & $77,20 \mathrm{a}$ & $46,40 \mathrm{a}$ & $46,05 \mathrm{a}$ \\
\hline 54 & $9,51 d$ & $1,62 d$ & $23,60 b$ & $0,93 b$ & $4,80 \mathrm{a}$ & $75,60 \mathrm{a}$ & $47,40 \mathrm{a}$ & $49,90 \mathrm{a}$ \\
\hline 26 & $9,33 d$ & $1,77 \mathrm{c}$ & $24,76 b$ & $0,76 \mathrm{c}$ & $5,00 \mathrm{a}$ & $79,60 \mathrm{a}$ & $50,50 \mathrm{~b}$ & $47,00 \mathrm{a}$ \\
\hline 12 & $9,19 \mathrm{~d}$ & $1,78 \mathrm{~b}$ & $25,80 \mathrm{a}$ & $0,68 \mathrm{c}$ & $5,65 a$ & $77,80 \mathrm{a}$ & $47,75 \mathrm{a}$ & $46,05 a$ \\
\hline 63 & $9,13 \mathrm{~d}$ & $1,74 \mathrm{c}$ & $25,64 a$ & $0,72 \mathrm{c}$ & $4,20 \mathrm{a}$ & $82,65 a$ & $51,45 b$ & $36,00 \mathrm{a}$ \\
\hline 97 & $8,99 d$ & $1,79 \mathrm{~b}$ & $24,69 b$ & $0,73 c$ & $4,60 \mathrm{a}$ & $76,15 a$ & $47,90 \mathrm{a}$ & $45,55 \mathrm{a}$ \\
\hline 4 & $8,86 \mathrm{~d}$ & $1,75 \mathrm{c}$ & $25,36 \mathrm{a}$ & $0,85 b$ & $4,85 \mathrm{a}$ & $75,65 a$ & $47,55 \mathrm{a}$ & $42,85 \mathrm{a}$ \\
\hline 62 & $8,80 \mathrm{~d}$ & $1,72 \mathrm{c}$ & $24,77 b$ & $0,70 \mathrm{c}$ & $4,60 \mathrm{a}$ & $79,20 \mathrm{a}$ & $52,40 \mathrm{~b}$ & $35,45 \mathrm{a}$ \\
\hline 96 & $8,79 d$ & $1,61 d$ & $24,79 b$ & $0,86 b$ & $6,60 \mathrm{a}$ & $77,20 \mathrm{a}$ & $46,65 a$ & $47,50 \mathrm{a}$ \\
\hline 85 & $8,77 d$ & $1,87 b$ & $25,58 \mathrm{a}$ & $0,63 \mathrm{c}$ & $6,75 a$ & $78,40 \mathrm{a}$ & $49,20 b$ & $44,95 \mathrm{a}$ \\
\hline 9 & $8,74 d$ & $1,65 c$ & $24,43 b$ & $0,70 \mathrm{c}$ & $4,65 a$ & $79,00 \mathrm{a}$ & $49,55 b$ & $50,65 a$ \\
\hline 121 & $8,70 \mathrm{~d}$ & $1,88 \mathrm{~b}$ & $27,32 \mathrm{a}$ & $0,55 \mathrm{c}$ & $4,02 \mathrm{a}$ & $78,05 \mathrm{a}$ & $46,85 a$ & $45,12 \mathrm{a}$ \\
\hline 13 & $8,63 d$ & $1,78 \mathrm{~b}$ & $25,91 \mathrm{a}$ & $0,78 \mathrm{c}$ & $4,60 \mathrm{a}$ & $79,40 \mathrm{a}$ & $49,25 b$ & $43,05 \mathrm{a}$ \\
\hline 130 & $8,48 d$ & $1,59 \mathrm{~d}$ & $21,68 b$ & $0,76 \mathrm{c}$ & $5,29 \mathrm{a}$ & $75,67 \mathrm{a}$ & $46,60 \mathrm{a}$ & $44,63 \mathrm{a}$ \\
\hline 109 & $8,42 d$ & $1,66 \mathrm{c}$ & $23,22 b$ & $0,89 b$ & $3,85 \mathrm{a}$ & $78,50 \mathrm{a}$ & $48,85 \mathrm{~b}$ & $38,05 \mathrm{a}$ \\
\hline 93 & $8,40 \mathrm{~d}$ & $1,55 \mathrm{~d}$ & $24,74 b$ & $0,91 b$ & $5,95 \mathrm{a}$ & $78,50 \mathrm{a}$ & $49,20 b$ & $46,85 a$ \\
\hline 58 & $8,35 \mathrm{~d}$ & $1,80 \mathrm{~b}$ & $25,06 \mathrm{a}$ & $0,76 \mathrm{c}$ & $5,25 \mathrm{a}$ & $77,65 a$ & $51,50 \mathrm{~b}$ & $38,70 \mathrm{a}$ \\
\hline 14 & $8,34 d$ & $1,73 \mathrm{c}$ & $26,42 \mathrm{a}$ & $0,63 \mathrm{c}$ & $4,55 \mathrm{a}$ & $78,55 a$ & $49,50 \mathrm{~b}$ & $38,90 \mathrm{a}$ \\
\hline 16 & $8,33 d$ & $1,80 \mathrm{~b}$ & $23,64 b$ & $0,71 \mathrm{c}$ & $6,50 \mathrm{a}$ & $77,30 \mathrm{a}$ & $48,75 b$ & $37,80 \mathrm{a}$ \\
\hline 17 & $8,32 d$ & $1,75 \mathrm{c}$ & $27,26 \mathrm{a}$ & $0,54 \mathrm{c}$ & $4,85 \mathrm{a}$ & $79,80 \mathrm{a}$ & $50,35 b$ & $50,05 \mathrm{a}$ \\
\hline 80 & $8,29 \mathrm{~d}$ & $1,65 c$ & $26,53 \mathrm{a}$ & $0,53 \mathrm{c}$ & $4,65 a$ & $77,55 \mathrm{a}$ & $47,55 \mathrm{a}$ & $48,45 \mathrm{a}$ \\
\hline Pioneiro & $15,26 \mathrm{a}$ & $2,08 \mathrm{a}$ & $25,42 \mathrm{a}$ & $0,59 \mathrm{c}$ & $4,75 a$ & $80,26 a$ & $51,09 b$ & $36,24 a$ \\
\hline Cameroon & $12,57 \mathrm{~b}$ & $1,87 \mathrm{~b}$ & $22,45 b$ & $0,88 b$ & $5,10 \mathrm{a}$ & $78,87 \mathrm{a}$ & $48,97 b$ & $39,81 \mathrm{a}$ \\
\hline Média & 9,94 & 1,76 & 24,89 & 0,78 & 4,98 & 78,07 & 48,88 & 43,54 \\
\hline
\end{tabular}

(1)Médias seguidas da mesma letra na coluna pertencem ao mesmo grupo de acordo com o teste Scott-Knott, a 5\% de probabilidade; MST, ALT e \%MS: médias de oito cortes; RFC: médias de quatro cortes de avaliação; PB, FDN, FDA e DIVMO: médias de um corte de avaliação. 
rene) e o milheto (espécie anual), uma das maiores preocupações é com a persistência apresentada pelos híbridos (Pereira et al., 2001). Os resultados observados confirmam essa preocupação, uma vez que, principalmente quanto à produção de matéria seca, notou-se redução da média do desempenho da maioria dos híbridos nos cortes sucessivos. Alguns materiais, contudo, apresentaram-se produtivos durante todo o período de avaliação, sugerindo a possibilidade de seleção de híbridos com boa persistência.

À exceção da porcentagem de PB e FDN, observaram-se diferenças significativas entre os híbridos nas análises de variância das características bromatológicas. Ausência de significância para a porcentagem de PB em capim-elefante também foi relatada por Botrel et al. (2000) e Daher (2003). Entretanto, Deschamps et al. (2001), estudando a composição bromatológica e a digestibilidade do colmo e das folhas, coletados em três partes da planta, de três cultivares de capim-elefante, detectaram diferenças significativas entre as cultivares quanto a todas as características e partes das plantas. Barreto et al. (2001) também encontraram diferenças significativas entre clones de capim-elefante quanto à porcentagem de $\mathrm{PB}$ e $\mathrm{FDN}$, e não quanto à digestibilidade in vitro da matéria seca.

Apesar das diferenças significativas observadas nas análises de variância quanto as demais características bromatológicas, nem sempre o teste de médias utilizado foi capaz de separar os híbridos em grupos (Tabela 2). Apenas houve a formação de grupos para FDA, apesar da grande amplitude de variação entre as médias dos híbridos para as diferentes características. Resultado semelhante foi observado por Daher (2003), que também verificou diferenças significativas na análise de variância e ausência de discriminação entre as médias das características bromatológicas em híbridos interespecíficos de Pennisetum spp.

Mesmo no caso da digestibilidade, em que a diferença nominal entre o melhor e o pior híbrido (29 e 45, respectivamente) foi de quase duas vezes (Tabela 2), não foi detectada diferença entre as médias pelo teste de Scott-Knott, apesar da boa precisão experimental (CV $=13,5 \%)$. Os procedimentos para comparações múltiplas, ou simplesmente testes de médias, são afetados, entre outras coisas, pela diferença entre as médias e pelo número de tratamentos. O teste de Tukey, por exemplo, com 100 tratamentos apresenta poder inferior a $50 \%$ para detectar diferenças de seis erros-padrões entre as médias, ao passo que, com cinco tratamentos, o valor é de 88\% (Ramalho et al., 2000). Resultados semelhantes foram apresentados por Silva et al. (1999) para o teste de Scott-Knott.

A fim de identificar os híbridos com maior potencial produtivo e com boa qualidade da forragem, foi utilizado o índice de seleção do somatório das classificações nas diferentes características avaliadas. Levando-se em conta apenas características de produção, os cinco melhores híbridos foram o 101, 53, 4, 36 e 13, os quais apresentaram as menores somas da classificação nas diferentes características (Tabela 3). As cultivares utilizadas como testemunhas (Pioneiro e Cameroon) mostraram-se semelhantes, com somatório igual a 159, sendo classificadas em $10^{\circ}$ e $11^{\circ}$ lugares.

Considerando-se apenas as características relacionadas à qualidade da forragem, os híbridos 39, 59, 113, 98 e 29 mostraram-se melhores (Tabela 3). Nesse caso as testemunhas foram classificadas em $128^{\circ}$ e $96^{\circ}$ lugares (Pioneiro e Cameroon, respectivamente), evidenciando o elevado potencial de utilização dos híbridos de capim-elefante e milheto no incremento da qualidade da forragem destinada à alimentação animal (Schank et al., 1993; Diz, 1994). Por fim, quando foram associadas todas as características avaliadas de produção e qualidade, os cinco primeiros classificados pelo índice de seleção foram os híbridos 39, 18, 96, 108 e 53 (Tabela 3). A cultivar Pioneiro ficou em 92o lugar e a Cameroon em 570. Deve-se destacar que o índice de seleção utilizado considera pesos iguais para as diferentes características avaliadas. Como a produção de matéria seca, normalmente, desperta maior interesse por parte dos produtores, buscou-se selecionar os híbridos que apresentaram melhor classificação nos índices de seleção de produção e geral. Por isso, os híbridos 108, 53, 35, 36 e 4 foram selecionados (Tabela 3). Esses clones serão avaliados em maior número de locais (Renace - Rede Nacional de Avaliação de Capim-elefante) para a confirmação do potencial forrageiro e futuro lançamento de cultivares.

Os resultados evidenciam que, embora os híbridos interespecíficos entre capim-elefante e milheto não tenham 
superado as testemunhas na produção de matéria seca, levando-se em consideração todas as características de interesse forrageiro, principalmente aquelas relacionadas à qualidade, os híbridos se destacam, apresentando potencial para o melhoramento do capim-elefante e para futuras recomendações aos produtores.

Tabela 3. Índices de seleção (IS) para as características de produção, bromatológicas e geral dos 40 melhores híbridos interespecíficos entre capim-elefante e milheto e das duas testemunhas.

\begin{tabular}{rrrcrc}
\hline Híbrido & IS & Híbrido & IS & Híbrido & IS \\
& produção & & bromatológicas & & geral \\
\hline 101 & 93 & 39 & 16 & 39 & 308 \\
53 & 133 & 59 & 43 & 18 & 320 \\
4 & 137 & 113 & 45 & 96 & 332 \\
36 & 137 & 98 & 53 & 108 & 335 \\
13 & 138 & 29 & 54 & 53 & 340 \\
94 & 142 & 52 & 60 & 57 & 342 \\
128 & 143 & 57 & 67 & 35 & 349 \\
78 & 156 & 60 & 73 & 98 & 350 \\
58 & 158 & 7 & 76 & 7 & 359 \\
35 & 161 & 40 & 90 & 52 & 359 \\
26 & 163 & 67 & 123 & 36 & 361 \\
106 & 164 & 79 & 129 & 4 & 365 \\
12 & 166 & 31 & 130 & 78 & 367 \\
121 & 168 & 33 & 131 & 12 & 369 \\
97 & 171 & 25 & 132 & 31 & 371 \\
108 & 173 & 96 & 132 & 30 & 373 \\
63 & 174 & 37 & 139 & 54 & 386 \\
66 & 174 & 30 & 144 & 122 & 390 \\
18 & 175 & 41 & 144 & 66 & 398 \\
85 & 179 & 18 & 145 & 79 & 401 \\
56 & 182 & 51 & 148 & 132 & 401 \\
104 & 185 & 84 & 149 & 59 & 402 \\
95 & 190 & 126 & 149 & 113 & 410 \\
96 & 200 & 72 & 151 & 97 & 416 \\
115 & 201 & 122 & 152 & 110 & 416 \\
129 & 202 & 28 & 153 & 41 & 420 \\
14 & 207 & 111 & 157 & 67 & 420 \\
42 & 208 & 1 & 158 & 27 & 422 \\
75 & 208 & 108 & 162 & 85 & 424 \\
15 & 209 & 54 & 164 & 72 & 425 \\
17 & 209 & 110 & 165 & 29 & 431 \\
93 & 211 & 132 & 172 & 126 & 432 \\
38 & 212 & 130 & 177 & 100 & 434 \\
62 & 212 & 5 & 180 & 33 & 437 \\
44 & 219 & 49 & 183 & 131 & 439 \\
90 & 219 & 100 & 184 & 60 & 446 \\
23 & 222 & 131 & 184 & 93 & 448 \\
54 & 222 & 27 & 185 & 49 & 449 \\
119 & 223 & 35 & 188 & 94 & 455 \\
16 & 228 & 117 & 200 & 103 & 462 \\
\hline Pioneiro & 159 & - & 454 & - & 613 \\
Cameroon & 159 & - & 352 & - & 511 \\
\hline Média & 181 & - & 146 & - & 402 \\
\hline & & & & &
\end{tabular}

\section{Conclusões}

1. Existe variabilidade entre os híbridos interespecíficos entre capim-elefante e milheto na maioria das características estudadas.

2. A superioridade apresentada por alguns híbridos, em relação às testemunhas, demonstra o potencial do cruzamento entre $P$. purpureum e P. glaucum para a obtenção de cultivares melhoradas.

\section{Referências}

BARRETO, G.L.; LIRA, M.A.; SANTOS, M.V.F.; DUBEUX JÚNIOR, J.C.B. Avaliação de clones de capim-elefante (Pennisetum purpureum Schum.) e de um híbrido com o milheto (Pennisetum glaucum (L.) R. Br.) submetidos a estresse hídrico. 2. Valor nutritivo. Revista Brasileira de Zootecnia, v.30, p.7-11, 2001.

BOTREL, M.A.; PEREIRA, A.V.; FREITAS, V.P.; XAVIER, D.F. Potencial forrageiro de novos clones de capim-elefante. Revista Brasileira de Zootecnia, v.29, p.334-340, 2000.

COMISSÃO DE FERTILIDADE DO SOLO DO ESTADO DE MINAS GERAIS. Recomendações para o uso de corretivos e fertilizantes em Minas Gerais: $5^{a}$ aproximação. Viçosa, 1999. 359p. DAHER, R.F. Cruzamentos dialélicos entre capim-elefante (Pennisetum purpureum Schum.) e milheto (Pennisetum glaucum L.) e suas relações com a divergência genética. 2003. 125p. Tese (Doutorado) - Universidade Estadual do Norte Fluminense Darcy Ribeiro, Campos dos Goytacazes.

DERESZ, F. Capim-elefante manejado em sistema rotativo para produção de leite e carne. In: PASSOS. L.P.; CARVALHO, L.A.; MARTINS, C.E.; BRESSAN, M.; PEREIRA, A.V. (Ed.). Biologia e manejo do capim-elefante. Juiz de Fora: Embrapa Gado de Leite, 1999. p.161-172.

DESCHAMPS, F.C.; BRITO, C.J.F.A. Qualidade da forragem e participação relativa de matéria seca de diferentes frações de cultivares de capim-elefante (Pennisetum purpureum Schumach.). Revista Brasileira de Zootecnia, v.30, p.1418-1423, 2001.

DIZ, D.A. Breeding procedures and seed production management in pearl millet $x$ elephant grass hexaploids hybrids. 1994. 118 p. Tese (Doutorado) - University of Florida, Gainesville.

FREITAS, F.V. Avaliação e seleção para pastejo de clones de capim-elefante (Pennisetum purpureum Schum.) e de um híbrido com o milheto (Pennisetum glaucum (E.) Leek). 2000. 105p. Dissertação (Mestrado) - Universidade Federal Rural de Pernambuco, Recife.

HANNA, W.W. Melhoramento do capim-elefante. In: PASSOS, L.P.; CARVALHO, L.A.; MARTINS, C.E.; PEREIRA, A.V. (Ed.). Biologia e Manejo do Capim-elefante. Juiz de Fora: Embrapa Gado de Leite, 1999. p.17-28.

JAUHAR, P.P. Citogenetics and breeding of pearl millet and related species. New York: Alan R. Liss, 1981. 289p.

PEREIRA, A.V.; MARTINS, C.A.; FILHO, A.B.C.; CÓSER, A.C.; TELES, F.M.; FERREIRA, R.P.; AMORIM, M.E.T.; ROCHA, A.F. 
Pioneiro - nova cultivar de capim-elefante para pastejo. In: REUNIÃO ANUAL DA SOCIEDADE BRASILEIRA DE ZOOTECNIA, 34., 1997, Juiz de Fora. Anais. Juiz de Fora: SBZ, 1997, p.102-104.

PEREIRA, A.V.; SOUZA SOBRINHO, F.; SOUZA, F.H.D.; LÉDO, F.J.S. Tendências do melhoramento genético e produção de sementes forrageira no Brasil. In: SIMPÓSIO SOBRE ATUALIZAÇÃO EM GENÉTICA E MELHORAMENTO DE PLANTAS, 4., 2003, Lavras. Melhoramento de plantas e produção de sementes no Brasil. Anais. Lavras, 2003, p.36-63.

PEREIRA, A.V.; VALLE, C.B.; FERREIRA, R.P.; MILES, J.W. Melhoramento de forrageiras tropicais. In: NASS, L.L.; VALOIS, A.C.C.; MELO, I.S.; VALADARES-INGLIS, M.C. Recursos genéticos e melhoramento de plantas. Rondonópolis: Fundação Mato Grosso, 2001. 1183p.

QUEIROZ FILHO, J.L.; SILVA, D.S.; NASCIMENTO, I.S. Produção de matéria seca e qualidade do capim-elefante (Pennisetum purpureum Schum.) cultivar Roxo em diferentes idades de corte. Revista Brasileira de Zootecnia, v.29, p.69-74, 2000.

RAMALHO, M.A.P.; FERREIRA, D.F.; OLIVEIRA, A.C. Experimentação em genética e melhoramento de plantas. Lavras: UFLA, 2000. 326p.
SANTOS, E.A.; SILVA, D.S.; QUEIROZ FILHO, J.L. Chemical composition of elephant grass var. Roxo cut at different heights. Revista Brasileira de Zootecnia, v.30, p.18-23, 2001.

SANTOS, M.C.S.; TABOSA, J.N.; DIAS, F.M.; FREITAS, E.V.; LIRA, M.A. Comportamento de clones de capim-elefante e de híbridos de capim-elefante $\mathrm{x}$ milheto no semi-árido do Nordeste do Brasil. Pesquisa Agropecuária Brasileira, v.29, p.16091615, 1994.

SANTOS, M.V.F.; DUBEUX JÚNIOR, J.C.B.; SILVA, M.C.; SANTOS, S.F.; FERREIRA, R.L.C.; MELLO, A.C.L.; FARIAS, I.; FREITAS, E.V. Produtividade e composição química de gramíneas tropicais na Zona da Mata de Pernambuco. Revista Brasileira de Zootecnia, v.32, p.821-827, 2003.

SCHANK, S.C.; DIZ, D.A.; BATES, D.B.; THOMPSON, K.E. Genetic improvement of napiergrass and hybrids with pearl millet. Biomass and Bioenergy, v.5, p.35-40, 1993.

SILVA, E.C.; FERREIRA, D.F.; BEARZOTI, E. Avaliação do poder e taxas de erro tipo I do teste de Scott-Knott por meio do método de Monte Carlo. Ciência e Agrotecnologia, v.23, p.687-696, 1999.

Recebido em 14 de maio de 2004 e aprovado em 7 de março de 2005 